\title{
Alternativo
}

\section{SAÚDE E MEIO AMBIENTE}

Gilson Guilherme de Albuquerque Farias (1)

Igor Rodrigues da Silva (2)

\begin{abstract}
Resumo
Este artigo apresenta uma reflexão sobre os avanços científicos e suas eventuais interferências sobre o meio ambiente. Mostra o resgate da ética da responsabilidade sugerida em obras produzidas no século XX, desde Max Weber até Hans Jonas. Faz uma avaliação crítica da ciência moderna e de seu braço armado, a tecnologia. Sugere a necessidade do ser humano agir com parcimônia e humildade diante do extremo poder transformador da tecnociência.
\end{abstract}

Palavras-chave: Bioética. Tecnociência. Meio ambiente. Vida humana.

\section{Introdução}

Políticas governamentais de todo o planeta tem se voltado para as questões ambientais. O respeito e a preservação do meio ambiente, bem como a valorização da vida humana tornaram-se uma preocupação global.

Uma nova consciência mundial tem procurado valorizar a qualidade de vida e à percepção de que a sobrevivência do homem depende diretamente da preservação dos recursos naturais.

Engelhardt Jr. (1996), enfatiza que, apesar de possuirmos conhecimentos tecnológicos, ainda não sabemos utilizá-lo com a necessária prudência ética. 
Vivemos atualmente a pós-modernidade, mencionada por Engelhardt, em que a tecnociência é dotada de um poder quase ilimitado de exploração da natureza. O aparato tecnológico assumiu um caráter de um poder quase incontrolável, onde a ciência e a técnica se sobressaem ante as necessidades do homem.

A ciência e a pesquisa, ainda são em grande parte financiadas e gerenciadas por instituições particulares, de interesses nem sempre claros a população. As novas tecnologias, vão adentrando o campo do conhecimento, modificando os já existentes e produzindo novos conceitos, muitas vezes sem a necessária reflexão ética. Os novos conhecimentos tendem a transformar-se em novas regras, que são impostas à sociedade, nem sempre esclarecida dos reais propósitos de tais descobertas.

\section{A Ciência e os Valores Humanos}

Husserl, numa famosa conferência sobre a crise da ciência européia, identificou uma falha no objetivismo do saber. Que este, apesar de ter desenvolvido tecnologias das mais refinadas, tem se tornado alheio às questões relacionadas à subjetividade humana e aos valores humanos essenciais da humanidade.

Segundo Morin, citado em Jonas (1995), esse tipo de negligência é fruto da ignorância sobre a ecologia de uma ação. Ou seja,, a partir do momento em que é iniciada, a ação humana escapa das mãos do agente, entrando em jogo as múltiplas interações próprias da sociedade e de um mercado econômico que a desviam de seu objetivo e, às vezes, lhe dão destino oposto ao inicialmente planejado. Nesse processo, a idéia de homem tende a se desintegrar. Observe-se por exemplo o caso de algumas especialidades médicas. Estas eliminaram a possibilidade de um ser humano biopsicosocial e, em lugar disso, este passa a ser conhecido através de pobres variáveis biológicas de acordo com as diferentes enfermidades que apresentar. Esse divórcio entre os avanços científicos e a reflexão ética foi que levou Jonas (1995) a propor novos parâmetros para avaliar a responsabilidade sobre os impactos das ações humanas, pois a técnica moderna introduziu ações de magnitudes tão grandiosas e imprevisíveis, que os marcos da ética anterior já não dão conta de contê-los.

Os marcos da ciência moderna se encontram em Descartes e Bacon, que concediam valorização extrema à experimentação. Ambos desprezavam o saber especulativo e privilegiavam o poder de intervenção da ciência. Neste caso, o ser humano passa a condição superior de poder manipular a natureza em seu próprio benefício. Em Avancements des 
Sciences Bacon incita os homens a unirem forças para dominar a natureza (RUSSEL, 1957). De fato, frente os homens de ciência têm feito todo o possível para responder à altura às propostas de Bacon. E, tanto foi feito, que se produziu um novo modelo de entrelaçamento entre a técnica e a ciência, de tal modo que toda investigação contemporânea se realiza através do íntimo diálogo entre o conceito e a aplicação, a teoria e a prática.

Em relação a isso Popper (1975) afirmou que: A história das ciências, como a de todas as idéias humanas, é uma história de sonhos irresponsáveis, de teimosia e de erros. Porém, a ciência é uma das raras atividades humanas, talvez a única, na qual os erros são sistematicamente assinalados e, com o tempo, constantemente corrigidos.

Dessa forma, torna-se fundamentalmente importante que cada um de nós, na condição de pesquisador ou cidadão, se questione sobre como deveremos considerar as vítimas da tecnociência, principalmente nos casos fatais. O que falar, por exemplo, sobre todos aqueles que sucumbiram por conta das guerras atômicas? Ou por uso indevido de armas químicas? Diante dessas atrocidades não se pode conceber que a ciência não esteja alicerçada numa sólida consciência ética do pesquisador, principalmente quando se leva em conta que ele não mais detém o poder absoluto sobre os processos de trabalho, mas sim, está a serviço de gestores do poder, que nem sempre cultivam preocupações dessa natureza.

Se podemos observar por um lado, que houve um avanço extraordinário da ciência, por outro se observa que este avanço, não necessariamente foi pautado na ética ou nos valores humanos que devem orientar as ações.

\section{A Ética na prática}

A bioética, hoje, propõe a reflexão crítica da prática científica. Amparada em autores como Beecher que, em depoimento prestado à Comissão do Congresso Estadunidense sobre procedimentos antiéticos identificados em pesquisas médicas, considerou que a ciência não é o valor maior, ao qual todos os outros devam se submeter. Beecher argumentou que a ciência sempre deveria estar subordinada a uma ordem de valores estabelecidos pela própria sociedade.

Parafraseando um pensador francês que por ocasião da II Guerra Mundial, disse ser a guerra um fato complexo demais para que a sociedade a deixasse somente nas mãos dos generais, diríamos que a biotecnociência é poderosa demais para que a deixemos sob a responsabilidade exclusiva dos cientistas. Há que se implementar o controle social dos 
avanços da ciência, sempre considerando, entretanto, a sábia ponderação de Hottois (1991), ao afirmar que tanto a recusa obscurantista, quanto a glorificação imprudente da biotecnociência, podem ser nefastas para a qualidade de vida das gerações futuras.

Diante dessas dificuldades em compatibilizar as diretrizes da tecnociência e o bem da humanidade, não faltam previsões apocalípticas como as de Ralph Lapp, citado por Toffler:

Estamos num trem que ganha velocidade constantemente, correndo por uma linha abaixo em que há um sem-número de controles de direção que levam a destinos desconhecidos. Nenhum cientista isoladamente acha-se na cabine de comando e é possível que haja demônios no painel de controle. A maior parte da sociedade acha-se no último vagão olhando para trás. (TOFFLER, 1995).

Toffler, um pouco mais ponderado, considera que virar as costas para a tecnologia é uma atitude irresponsável, e até mesmo, imoral. Para ele, é necessário definir uma estratégia poderosa para evitar o choque do futuro e criar mecanismos de regulamentação a partir da consciência sobre os efeitos e impactos do progresso tecnológico. Para tanto, torna-se imperiosa uma nova mudança de paradigma.

$\mathrm{Na}$ Antigüidade, a cultura grega dispunha de um saber de grande alcance, mas que não produzia grandes transformações, atualmente, ao contrário, o saber tem forte apelo técnico e se faz acompanhar de um extraordinário poder de mudar a realidade social e o ambiente natural. Porém, como o saber moderno está desamparado da reflexão ética, tem-se a impressão que podemos estar todos num mesmo barco desgovernado sob a tempestade. Ao se considerar a responsabilidade das ações humanas, deve-se enfatizar que somente o ser humano é capaz de mudar o curso da história da vida com suas intervenções. Os rumos são diversos, assim como o destino final. Uma vereda pode terminar num precipício, enquanto outra numa fonte de águas puras.

Os mesmos impasses são apresentados pela biotecnociência, que nos coloca frente a frente com decisões cada vez mais angustiantes. Uma escolha que somente ganha contornos apropriados por um processo de deliberação conjunta, que envolva toda sociedade humana, tal como propõe Habermas. A responsabilidade de cada ser humano consigo mesmo é indissociável da responsabilidade que se tem para com todos os homens. Trata-se de uma solidariedade que nos liga a todos, os homens e a natureza que nos cerca. 
É importante e obrigatório reconhecer que, presentemente, a reflexão ética é levada a intervir num contexto novo de conhecimento, pois a tecnociência transformou profundamente, não apenas o conceito de natureza, mas a própria natureza. A antiga idéia de natureza acomodava-se à inatingível ordem natural, que definia os contornos das normas éticas. Hoje, trabalhamos com uma concepção inteiramente distinta. $\mathrm{O}$ curso da existência não é mais dependente de uma lei superior que reserva ao ser humano a condição de espectador.

Hoje o homem é o agente das transformações e tem à sua mercê toda a existência, intervindo nela como bem lhe apraz. A natureza, portanto, passou a ser considerada apenas como propriedade, como domínio do homem. Diante dessa realidade, é impossível não submeter as ações da ciência às exigências de uma nova responsabilidade ética. Eco (1973) faz apreciação bastante apropriada sobre uma nova percepção de responsabilidade:

O progresso material do mundo agudizou minha sensibilidade moral, ampliou minha responsabilidade, aumentou minhas possibilidades, dramatizou minha impotência. Ao fazer-me mais difícil ser moral, faz com que eu, mais responsável que meus antepassados e mais consciente, seja mais imoral que eles e minha moralidade consiste precisamente na consciência de minha incapacidade.

Esta responsabilidade que nos é imposta, pede que se preserve a condição de existência da humanidade, mostra a vulnerabilidade que o agir humano impõe a fragilidade natural da vida. A manutenção da natureza é a condição de sobrevivência do ser humano. Preservar a natureza significa preservar a vida. Eis por que, tornou-se uma obrigação do ser humano o mais absoluto respeito à natureza.

Outrossim, é elementar o conhecimento das repercussões sobre a saúde humana, decorrentes da deterioração do meio ambiente. Os possíveis desequilíbrios que ocorrerão em conseqüência do superaquecimento do planeta, ou da progressiva destruição da camada de ozônio ou, ainda, do incontrolável desmatamento das já escassas reservas florestais já se faz sentir em alguns pontos do planeta. Assim, no momento atual, representa-se um futuro que talvez não se realize, mas que, no entanto, apresenta seu testemunho no presente.

Este mostra eloquentemente a necessidade de se instituir um novo estatuto de responsabilidade que vise a manutenção da vida humana. Prigogine (1996) aponta a necessidade da ciência dialogar com a natureza, alertando que compreender não pode significar controlar, pois: 
Seria cego o senhor que acreditasse conhecer seus escravos pelo simples fato dos mesmos obedecerem às suas ordens (...) Nenhuma especulação, nenhum saber jamais afirmou a equivalência entre o que se faz e o que se desfaz, entre uma planta que nasce, floresce e morre, e uma planta que ressuscita, rejuvenesce e retorna para sua semente primitiva, entre um homem que amadurece $e$ aprende e um homem que se torna progressivamente criança, depois embrião, depois célula.

As inquietações com o desequilíbrio ecológico derivam também do quase inexistente sistema de contabilidade ambiental. O sistema internacionalmente aceito para apresentar o progresso econômico de um país, o chamado Produto Interno Bruto (PIB), não considera a depreciação do capital natural, como é o caso da perda do solo por erosão, da destruição das florestas pela chuva ácida ou da redução da camada de ozônio. O resultado é que a contabilidade econômica superestima o progresso técnico e desconsidera a degradação ambiental. O sistema de avaliação do equilíbrio do meio ambiente é bastante precário e sequer temos idéia do número de espécies de plantas e animais que desaparecem a cada ano. A conseqüência natural de uma economia baseada em apreciações tão precárias é a de que, pouco a pouco, se esvai a vida do planeta. As práticas danosas à natureza que foram implantadas nas últimas décadas traduzem-se agora, por uma redução de terras agriculturáveis, de bosques e pastagens e da vida marinha, além das drásticas alterações climáticas e dos fenômenos a estas relacionados, como os cada vez mais freqüentes furacões e terremotos.

Em decorrência disso, são crescentes os gastos com projetos de descontaminação ambiental, com o tratamento de enfermidades como o câncer de pele, patologias congênitas, diferentes formas de alergias, enfisema pulmonar, asma brônquica e outras doenças respiratórias. A contaminação ambiental, particularmente da água, do ar e do solo por produtos tóxicos, os gastos com agravos à saúde humana estão crescendo expressivamente. Acima de tudo, porém, é impressionante o aumento dos custos humanos decorrentes da expansão do fenômeno da fome, que se amplia nesse processo vertiginoso.

Com relação ao avanço incontrolado da biotecnociência, assim se expressou Berlinguer (1993): A velocidade com que se passa da pesquisa pura para a aplicada é, hoje, tão alta que a permanência, mesmo que por breve tempo, de erros ou fraudes, pode provocar catástrofes. 
Morin (1995), nos alerta que: estamos perdidos, irremediavelmente perdidos. Estamos perdidos, mas temos um teto, uma casa, uma pátria. É a nossa pátria, o lugar de nossa comunidade de destino de vida e morte. O evangelho dos homens perdidos nos diz que devemos ser irmãos, não porque seremos salvos, mas porque estamos perdidos.

Finalmente, as palavras sensatas de Potter (1998), nos convoca: Peço-lhes que pensem a bioética como uma nova ética da ciência que combine humildade, responsabilidade e competência, que seja interdisciplinar e intercultural e que faça prevalecer o verdadeiro sentido de humanidade.

Em resumo, a bioética é uma ferramenta indispensável para a construção de uma ciência pautada na ética, que responde aos dilemas humanos, dos indivíduos e das populações, respeitando as formas de vida e o ambiente. Para tanto, a bioética deve ter como meta trazer para a pauta de discussão, temas que possam constituir-se em marcos orientadores de reflexões capazes de tornar o planeta de fato, um lugar para se viver plenamente.

\section{Referências}

BERLINGUER,G. Questões de vida: ética,ciência e saúde. São Paulo, Hucitec, 1993.

COMISIÓN MUNDIAL DEL MEDIO AMBIENTE Y DEL DESARROLLO. Nuestro futuro común. Madrid, Alianza Editorial, 1992.

ECO, U. De la responsabilidad moral como producto tecnológico: diario mínimo, Barcelona, Península, 1973.

ENGELHARDT JR., HT. The foundations of bioethics. London, Oxford University Press, 1996

HOTTOIS, G. El paradigma bioético: una ética para la tecnociencia. Barcelona, Anthropos, 1991.

JONAS, H. El principio de responsabilidad: ensayo de una ética para la civilización tecnológica. Barcelona, Herder, 1995.

MORIN, E. \& KERN, AB. Terra-pátria. Porto Alegre, Sulina, 1995.

POPPER, K. A Lógica da Pesquisa Científica. São Paulo, Cultrix, Edusp, 1975.

POTTER, VR. Bioética puente, bioética global y bioética profunda. Acta Bioethica, 7:23-33, 1998.

PRIGOGINE, I. O fim das certezas. São Paulo, Unesp, 1996. 
RUSSEL, B. História da filosofia ocidental. São Paulo, Companhia Editora Nacional, 1957

TOFFLER, A. El shok del futuro. Barcelona, Plaza y Janés, 1995.

\section{Sobre os autores:}

(1) Gilson Guilherme de Albuquerque Farias é Engenheiro Florestal e Mestre em Desenvolvimento Regional. Desenvolve trabalhos com ênfase nas questões ambientais. E-mail: gilson610@hotmail.com;

(2) Igor Rodrigues da Silva é Bacharel em Direito pelas Faculdades Integradas Barros de Melo e PósGraduado pelo Centro de Estudos Jurídicos Martorelli - Faculdade Maurício de Nassau - PE.

E-mail: igorrodrigues@nassau.com.br 